\title{
Research Paper: The Effectiveness of Emotion Coaching Parenting Program in Iranian Preschool Children With Internalizing Disorders
}

Pegah Pezeshki ${ }^{1}$ (1), Hoda Doos Ali Vand ${ }^{* *}$ (1), Maryam Aslzaker ${ }^{1}$ (i), Mehdi Jafari ${ }^{1}$ (1)

1. Department of Clinical Psychology, School of Medicine, Shahid Beheshti University of Medical Sciences, Tehran, Iran

\begin{tabular}{|c|c|}
\hline $\begin{array}{l}\text { Use yuur device to scan } \\
\text { and read he article online }\end{array}$ & \\
\hline 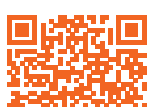 & $\begin{array}{l}\text { Cltertion: Pezeshki, P., Doos Ali Vand, H., Aslzaker, M., \& Jafari, M. (2020). The Effectiveness of Emotion Coaching Parenting } \\
\text { Program (ECPP) in Iranian Preschool Children With Internalizing Disorders. Journal of Practice in Clinical Psychology, 8(3), } \\
\text { 203-216. https://doi.org/10.32598/jpcp.8.3.676.2 }\end{array}$ \\
\hline aryots & doi) https://doi.org/10.32598/jpcp.8.3.676.2 \\
\hline
\end{tabular}

(c) (i) (s)

\section{Article info:}

Received: 21 Apr 2020

Accepted: 10 Jul 2020

Available Online: 01 Jul 2020

Keywords:

Internalizing disorders, Emotion coaching, Emotion regulation, Emotional awareness

\section{ABSTRACT}

Objective: Emotion Coaching Parenting Program (ECPP) is one of the treatment programs focused on emotions and targets the way parents and children interact emotionally. Although the effectiveness of ECPP on children with internalizing disorders has been proved previously, the effects of this program have not been investigated in Iranian preschoolers with a range of internalizing disorders. Therefore, the aim of the current study was to examine the effects of ECPP when used by mothers of preschoolers with internalizing disorders.

Methods: The current randomized controlled trial was done on 31 participants who were randomly assigned to the $\mathrm{ECPP}(\mathrm{n}=15)$ and control $(\mathrm{n}=16)$ groups that completed all treatment sessions. Data were collected at three stages of pre-intervention, post-intervention, and 3-months follow-up, using Difficulties in Emotion Regulation Scale, Emotion Regulation Checklist, Achenbach's Child Behavior Checklist, and Maternal Emotional Styles Questionnaire.

Results: Repeated measures ANOVA tests were conducted to test differences between the intervention and control groups for maternal emotion regulation and maternal emotion coaching. The results indicated significant improvements in emotional awareness and emotion regulation of mothers in the intervention group at post-intervention and follow-up compared with the pre-intervention, while no significant improvements were found in the control group. Children in both groups showed improvements in emotional lability/negativity at post-intervention, but the improvements were significantly higher in the intervention group. Children of the intervention group also showed higher improvements in emotion regulation compared with the control group. Additionally, significant reductions in the symptoms of children's internalizing disorders at post-intervention and follow-up were observed in the intervention group compared with the control group.

Conclusion: ECPP can be one of the effective treatments for reducing the symptoms of children's internalizing disorders and improving the emotion regulation of parent and child. 


\section{Highlights}

- ECPP treatment improves maternal emotion regulation.

- ECPP treatment improves mothers' emotional awareness.

- ECPP treatment improves emotional lability/negativity in children.

- ECPP treatment improves children's emotional regulation.

- ECPP treatment improves the symptoms of internalizing disorders in children.

\section{Plain Language Summary}

One of the necessities in maternal care, especially for children with behavioral problems, is the emotion regulation and emotional awareness of mothers. This issue means that a mother who could not have successful mastery over her various emotions would not convey emotion regulation and emotional awareness to her child. One of the psychological programs that can help mothers with this task is ECPP treatment. Our results showed that this treatment improves mothers' emotion regulation and emotional awareness. This treatment is also useful in improving the emotion regulation and emotional awareness of their children, and this, in turn, improves the behavioral problems of children.

\section{Introduction}

nternalizing disorders, including anxiety and depression, are the most prevalent mental disorders in children and teenagers (In-Albon, 2012), which frequently persist into adulthood (Davis, Votruba-Drzal \& Silk, 2015). Mean global prevalence for anxiety and depression in children and teenagers has been estimated at 3.21\% and $6.16 \%$, respectively (Erskine et al., 2017). In Iran, according to parents' reports, the prevalence of emotional and behavioral disorders among children has been estimated at 15.8\% (Ghanbari, Esmaili, Porebrahim \& Kholghi, 2017). Previous studies have demonstrated that internalizing problems tend to increase with age (Achenbach, Howell, Quay \& Conners, 1991; Gilliom $\&$ Shaw, 2004). These groups of disorders are associated with over-controlled behaviors that are considered to be inner-directed (Sanders, Merrell \& Cobb, 1999).

According to the latest revision of "diagnostic and statistical manual of mental disorders" (DSM-5), depression, anxiety, and somatic symptoms are the primary types of internalizing disorders in children (APA, 2013). Contextual factors, interpersonal factors, and child characteristics have been identified as the risk factors for internalizing symptomatology (Crespo, Trentacosta, Aikins \& Wargo-Aikins, 2017). As internalizing disorders nega- tively impact functioning, early diagnosis is important (Sanders et al., 1999). On the other hand, these disorders are difficult to detect in preschoolers due to the less welldeveloped verbal skills and limited capacity to describe internal feeling states (Tandon, Cardeli \& Luby, 2009).

Children with internalizing disorders show emotional deficits, such as poor emotional awareness and emotion dysregulation (Eisenberg et al., 2001; Kim \& Cicchetti, 2010). Based on developmental research, emotion regulation is a necessary component of children's successful development that leads them to regulate emotional responses and related behaviors in socially adaptive and appropriate ways (Morris, Silk, Steinberg, Myers \& Robinson, 2007). Emotion regulation is a multi-faceted construct involving external and internal processes, by which one manages the monitoring, evaluating, and modifying emotional reactions to accomplish individual goals and facilitate adaptation to the social environment (Thompson, 1994).

Findings of different studies emphasize the association between childhood emotion regulation ability and secure attachment (Kidwell et al., 2010), inhibitory control of attention (Carlson \& Wang, 2007), early educational success (Graziano, Reavis, Keane \& Calkins, 2007; Ivcevic \& Brackett, 2014), and social adaptive competence and prosocial behaviors (Eisenberg, 2001), while difficulties with emotion regulation are linked to physiological stress responses (de Veld, Riksen-Walraven \& de 
Weerth, 2012), serious behavior problems during childhood (Zeman, Shipman, \& Suveg, 2002), and later social problems and delinquency (Trentacosta \& Shaw, 2009).

Although emotion regulation skills develop in childhood, adolescence, and beyond (Crespo et al., 2017), rapid maturation of emotion regulation skills occurs in the early childhood period (Harden et al., 2017). During this period, the caregivers serve as a major context for emotion regulation development (Crespo et al., 2017). Based on research in normative development, emotion regulation skills seem to develop primarily inside the parent-child relationship (Shipman \& Zeman, 2001). Parents play an important role in the quality of children's preliminary emotional capabilities. During early childhood, parents proceed to socialize their children's emotional skills through some ways, such as emotional talks, clarification of the causes and outcomes of emotions, and reactions to children's expressed emotion (Lunkenheimer, Shields \& Cortina, 2007).

According to Crespo et al. (Crespo et al., 2017) children's emotion regulation difficulties were regarded as the indirect interrelation between mothers' lower emotion awareness and children's internalizing problems. The concept of emotion socialization can lead us to the construct of the "meta- emotion philosophy" (PMEP), which refers to "adaptive and maladaptive thoughts and feelings that parents have about their children's emotions and their own emotions" (Gottman, Katz \& Hooven, 1996). Based on Gottman et al. (Gottman et al., 1996), parental differences in MEP leads to variant parenting styles: "emotion coaching (EC)" and "emotion dismissing (ED)". Emotion coaching parenting program (ECPP) is described as "parents' emotional awareness within themselves and their children, and the ability to use this awareness to benefit their children's socialization” (Lagacé-Séguin \& Coplan, 2005).

Previous studies have highlighted the important association between EC and childhood internalizing problems (Edrissi, Havighurst, Aghebati, Habibi \& Arani, 2019; Ellis, Alisic, Reiss, Dishion \& Fisher, 2014; Gus, Rose \& Gilbert, 2015; Havighurst, Wilson, Harley, Prior \& Kehoe, 2010; Loop \& Roskam, 2016; Sanders et al., 1999). For example, the results of a pilot study by Edrissi et al. (Edrissi et al., 2019) indicated that the "Tuning into Kids (TIK) program" had positive effects on Iranian preschool children with anxiety problems. Results of a community trial by Havighurst et al. (Havighurst et al., 2010) in Australia also comes to the aid for the efficacy of a parenting intervention targeting parent emotion socialization practices that lead to enhanced child emotional knowledge and behavior. It seems that progress in parents' EC improves their behavioral and emotional response towards their children. Findings from a micro- trial study in Belgium (Loop \& Roskam, 2016) demonstrated that compared with the control group, parents whose ECPP had been stimulated showed higher levels of positive affect and were more emotionally tactful during free play. In succession, children of these parents indicated higher levels of persistence and enthusiasm, but only when they had to grapple with negative emotional arousal during frustration tasks.

Accordingly, a children's capability to effectively regulate their emotions plays a vital role in their successful development and leads to social competence (Ellis et al., 2014). Positive emotions, such as happiness promote one's physical, cognitive, and emotional-social development and moderate the impact of stressors on his or her mental health (Harden et al., 2017). As the authors know, no previous study has examined the effects of ECPP on Iranian preschoolers with different internalizing disorders (i.e. depression, anxiety, and psychosomatic symptoms). Although children's internalization problems expose them to all aspects of their individual, family, and social life (Shiri, Valipour, Mazaheri \& Roudbari Saghaee, 2014), studies on behavioral problems, including internalization problems, have been limited to high school students in Iran. It was hypothesized that relative to the control group, the ECPP would be more effective in decreasing the symptoms of children's internalizing disorders and improving the emotion regulation of mothers and their children. Therefore, the aim of the current study was to investigate the effects of ECPP in a sample of Iranian preschoolers identified with internalizing disorders

\section{Method}

\section{Participants}

The purposive sampling method was used and the samples consisted of 31 adult women and their children $(64 \%$ girls; 36\% boys; 3-5 years) who were recruited from seven kindergartens in lower to middle-class socio-economic regions in Tehran during the years 2018 to 2019. Forty-five percent of children were firstborn in the family. All mothers were married and $93 \%$ of mothers were housewives. Twelve mothers (38.70\%) had completed high school and others had higher educational degrees (bachelor and master). Most of the mothers were not in paid work $(70.96 \%)$ and counted on their husbands for financial support. No significant variations were found between the two groups in the age of mothers. 


\section{Procedure}

The participants of the current randomized controlled trial were randomly assigned to the ECPP or control groups. Kindergarten directors informed mothers and volunteer mothers were subsequently contacted by the researcher. Then, 150 mothers who were interested in participating in the study were asked to complete the "Child Behavior Checklist" (CBCL) (Achenbach \& Rescorla, 2000). The inclusion criteria for the present study were scoring one $\mathrm{SD}$ above the mean for the $\mathrm{CBCL}$, at least high school education, and mothers' age range of 20-40 years. Mothers were excluded from the study if they were receiving concurrent psychotherapy during the study, or if their children had a principal diagnosis of communication or serious developmental disorder according to the DSM-5. Thirty-seven preschoolers were rated by their mothers as scoring at least one SD upon the mean for the CBCL $(t=65)$ and met other inclusion criteria. Eligible participants $(n=37)$ were randomly assigned to the ECPP and control groups. Of the 37 participants, six subjects dropped out prior to completing the treatment. Finally, 31 participants completed all treatment sessions.
ECPP group attended a seven-session ECPP on a weekly basis. Mothers completed study measures during preintervention (Time 1), post-intervention (Time 2), and at a 3- months follow-up (Time 3). After the final follow-up assessment, the control group was offered the ECPP.

\section{Treatment}

The program was based on Gottman's emotion coaching theory and practice (Gottman \& DeClaire, 1997). According to Gottman (Gottman \& DeClaire, 1997; Gottman et al., 1996), EC includes five components: 1. "Awareness of the child's emotion"; 2. "Considering emotion as an opportunity for intimacy and teaching"; 3. "Listening empathically and validating the child's feelings"; 4. "Naming and labeling the emotions"; and 5. "Setting limits while helping the child problem-solving". The program was provided in a group format, for $2 \mathrm{~h}$ per week for seven weeks. All therapy sessions were delivered by the main therapist (the first author). One booster session was held one month after the initial seven sessions (Table 1). Different exercises in the program were provided to teach Gottman's five steps, with content specified as core, optional, or home activities (Edrissi et al., 2019).

Table 1. Treatment protocol and content of group therapy sessions

\begin{tabular}{|c|c|}
\hline Sessions & Content of Treatment Sessions \\
\hline First & $\begin{array}{l}\text { - Introduction, acquaintance, and initial communication between members and the researcher } \\
\text { - Providing comprehensive explanations about the concept of meta- emotion philosophy } \\
\text { - Explaining about the two styles of preparation and emotional neglect }\end{array}$ \\
\hline Second & $\begin{array}{l}\text { - Introduction to the concept of emotions and emotion regulation approach } \\
\text { - Investigating and identifying physiological aspects in the experience of emotions } \\
\text { - Examining the differences between thoughts, emotions, and behaviors }\end{array}$ \\
\hline Third & $\begin{array}{l}\text { - focus on the mothers' own emotions and familiarize them with the concept of emotional awareness } \\
\text { - Talking about how the mother's emotional awareness affects the child } \\
\text { - Explaining the concept of empathy, its importance in the mother-child relationship, and its distinction from empathy }\end{array}$ \\
\hline Fourth & $\begin{array}{l}\text { - Teaching the first stage of emotional preparation: Awareness of the child's emotions. } \\
\text { - Teaching the second stage of emotional preparation: Considering the child's emotions as an opportunity for more inti- } \\
\text { macy in the relationship with the child and his education. } \\
\text { - Specifying homework appropriate to the meeting }\end{array}$ \\
\hline Fifth & $\begin{array}{l}\text { - Teaching the third stage of emotional preparation: empathetic listening to the child's profession and validating his feelings } \\
\text { - Teaching the fourth stage of emotional preparation: helping the child to write down his emotions } \\
\text { - Specifying homework appropriate to the meeting }\end{array}$ \\
\hline Sixth & $\begin{array}{l}\text { - Learning the fifth stage of emotional preparation: setting boundaries for the child and at the same time helping him to } \\
\text { solve his problems } \\
\text { - Review of the previous steps } \\
\text { - Determining homework appropriate to the meeting }\end{array}$ \\
\hline Seventh & $\begin{array}{l}\text { - Final evaluation (post-test) } \\
\text { - Discussion about the meetings and examining the feelings of the group members towards the process of the meetings } \\
\text { and its end. }\end{array}$ \\
\hline
\end{tabular}


The program inspired modifications in parenting attitudes and behaviors while increasing the emotional contact between parents and children. Parents were instructed on the five steps of EC by means of a series of role-plays, exercises, and psychoeducation. In the first three sessions, parents were instructed to be attentive to children's lowerintensity emotions, and how to reflect, label, and empathize the child's emotion. The fourth session was dedicated to problem-solving, and the next two sessions concentrated on more intense emotions, specifically anger, and involved emotion regulation strategies, such as slow breathing, relaxation, etc. Parents were also taught skills in comprehending and regulating their own emotions and were informed about the impact of family of origin experiences on their beliefs and responses to emotions (Edrissi et al., 2019; Havighurst et al., 2010). The final session included summaries of key points provided during the six sessions, an open discussion about each participant's personal experience during sessions, and a closing statement from each participant.

\section{Instruments}

\section{Difficulties in Emotion Regulation Scale (DERS)}

Difficulties in Emotion Regulation Scale (DERS), a 36item self-report questionnaire that was designed by Gratz \& Roemer in 2004, measures difficulties with multiple aspects of emotion regulation. Respondents score how often the items that are emotion-related, apply to them on a 5-point scale (from 1: "Almost Never" to 5: "Almost Always"). High scores show more difficulties in emotion regulation (Gratz \& Roemer, 2004). Factor analyses has approved six DERS factors, including "nonacceptance of emotional responses", "difficulties engaging in goal-directed behavior", "impulse control difficulties", "lack of emotional awareness", "limited access to emotion regulation strategies", and "lack of emotional clarity". Internal consistency of the DERS is good: Cronbach alphas of 0.80 and above have been reported for all subscales (Gratz \& Roemer, 2004). Internal consistency of the Persian Version of DERS using Cronbach's Alpha for all subscales ranged from 0.86 to 0.88 . Furthermore, test-retest coefficients for a one-week interval ranged from 0.79 to 0.91 (Khanzadeh, Saeediyan, Hosseinchari \& Edrissi, 2012).

\section{Maternal Emotional Styles Questionnaire (MESQ)}

Mothers' attitudes towards EC were assessed via the Maternal Emotional Styles Questionnaire (MESQ). This 14item instrument was developed to assess maternal EC and ED styles (Lagacé-Séguin \& Coplan, 2005). MESQ asks mothers to rate how much they agree or disagree with the individual statements on a scale ranging from 1 ("strongly disagree") to 5 ("strongly agree"). In the original Canadian version of the scale, Cronbach's alpha for two factors of this questionnaire has been reported 0.92 (for EC) and 0.90 (for ED). (Lagacé-Séguin \& Coplan, 2005). In the Persian version of the MESQ, the questionnaire showed good internal consistency. The re-administration of this measure a month later yielded a strong correlation ( $\mathrm{r}=$ $.47 ; \mathrm{P}<0.001)$. Factor analysis has been indicated that two factors (EC and ED) accounted for $45.44 \%$ of the total variance (Soleimani \& Bashash, 2012).

\section{Child Behavioral Checklist (CBCL)}

This instrument developed by Achenbach and Rescorla (Achenbach \& Rescorla, 2000) consists of 99 items assessing behaviors of 6-18 years old children within the past 6 months. CBCL evaluates psychopathology across internalizing and externalizing disorders in sub-clinical and clinical levels (Crespo et al., 2017). CBCL contains 8 scales of the narrowband syndrome, including emotionally reactive, somatic complaints, anxiety/depression, withdrawal, sleep problems, attention problems, aggressive behaviors, and other problems (Pourhossein et al., 2015). An internalizing problem score is derived from symptoms on the anxiety/ depression, withdrawal, and somatic complaints subscales (Esbensen et al., 2018). T-scores were also calculated for scales of internalizing problems, with values above 65 indicating clinically-significant problems (Crespo et al., 2017). According to Achenbach and Rescorla (Achenbach, Dumenci \& Rescorla, 2003; Achenbach \& Rescorla, 2003), CBCL has strong test-retest reliability with correlation coefficients for the individual items ranging from 0.37 to 0.91 . Test-retest reliability of the Persian Version of CBCL was also good, with correlation coefficients ranging from 0.37 to 0.91 for each item (Mohammad-Esmail, 2009).

\section{Emotion Regulation Checklist (ERC)}

ERC was developed by Shields \& Cicchetti (Shields \& Cicchetti, 1997) in order to assess parents' perceptions of the child's emotionality and regulation at the age of 6-12. This scale consists of 24 items, which are scored on a 4-point Likert scale (1: Never; 2: Sometimes; 3: Often; 4: Almost always). ERC contains two subscales: Lability/Negativity and Emotion Regulation. The emotion regulation subscale (consisting of eight items) assesses key processes for adaptive regulation that includes empathy and the display of socially appropriate emotions. The lability-negativity subscale (consisting of 15 items) evaluates arousal, reactivity, anger outbursts, and mood swings (Danisman, Dereli, Akin \& Yaya, 2016; Shields \& Cicchetti, 1997). 
Cronbach's alpha for two subscales of this questionnaire have been reported 0.96 (for Lability/Negativity subscale) and 0.83 (for Emotion Regulation subscale), respectively (Shields \& Cicchetti, 1997). The emotion regulation composite score is produced from the aggregation of these two subscales with the internal consistency of 0.89 that captures both regulation and dysregulation of the emotions (Danisman et al., 2016). For the purpose of the current study, ERC was validated in a sample of Iranian preschool children. The results indicated high internal consistency (Cronbach's alpha= 0.94) for the Persian version of the ERC.

\section{Results}

Mean \pm SD of maternal emotion regulation and maternal EC and ED are presented in Table 2. Repeated measures ANOVA was conducted in order to test the differences between both groups for maternal emotion regulation and maternal EC. Kolmogorov-Smirnov test was used to assess the normality of the variables And the results showed that they were distributed normally in both groups. The assumption of homogeneity of variance was evaluated using Levene's test and results showed the violation of homogeneity of variance $(\mathrm{P}>0.05)$. Mauchly's Test of Sphericity was conducted to determine the equality of variance-covariance matrices. Based on the results, it was concluded that the assumption of sphericity was established. The group (ECPP vs. control) was defined as the between-subject variable, and time (pre-intervention, post-intervention, and follow-up) as the within-subject variable.

This made it possible to examine the changes of the within-subject analysis over time, as well as comparing the two groups (between-subject analyses across the group), which enabled us to examine whether changes were limited to those in the ECPP group. Results of repeated measures ANOVA for between-group effects

Table 2. Mean \pm SD and repeated measures ANOVA results for the emotion regulation and emotion coaching

\begin{tabular}{|c|c|c|c|c|c|c|c|}
\hline \multirow{3}{*}{ Variable } & \multirow{3}{*}{ Group } & \multicolumn{3}{|c|}{ Adjusted Mean } & \multirow{2}{*}{\multicolumn{3}{|c|}{ Group-by-Time Interactior }} \\
\hline & & \multicolumn{3}{|c|}{ Mean $\pm S D$} & & & \\
\hline & & Pre-Intervention & Post-Intervention & Follow-up & Analysis (F) & df & $\eta^{2}$ \\
\hline \multirow{2}{*}{$\begin{array}{l}\text { Difficulties engaging in } \\
\text { goal-directed behavior }\end{array}$} & Intervention & $12.67 \pm 2.77$ & $11.40 \pm 2.61$ & $8.47 \pm 2.03$ & \multirow{2}{*}{$7.44 * * *$} & \multirow{2}{*}{2,58} & \multirow{2}{*}{0.20} \\
\hline & Control & $13.06 \pm 1.73$ & $13.75 \pm 3.15$ & $13.63 \pm 1.82$ & & & \\
\hline \multirow{2}{*}{$\begin{array}{c}\text { Impulse control difficul- } \\
\text { ties }\end{array}$} & Intervention & $14.73 \pm 3.59$ & $12.13 \pm 2.95$ & $10.73 \pm 2.96$ & \multirow{2}{*}{2.29} & \multirow{2}{*}{2,58} & \multirow{2}{*}{0.07} \\
\hline & Control & $14.19 \pm 4.56$ & $13.69 \pm 3.61$ & $13.44 \pm 5.10$ & & & \\
\hline \multirow{2}{*}{$\begin{array}{c}\text { Lack of emotional aware- } \\
\text { ness }\end{array}$} & Intervention & $15.40 \pm 2.61$ & $12.40 \pm 2.77$ & $9.27 \pm 2.15$ & \multirow{2}{*}{$8.49 * * *$} & \multirow{2}{*}{2,58} & \multirow{2}{*}{0.23} \\
\hline & Control & $15.31 \pm 3.24$ & $15.00 \pm 3.29$ & $15.31 \pm 3.74$ & & & \\
\hline \multirow{2}{*}{$\begin{array}{l}\text { Limited access to emotion } \\
\text { regulation strategies }\end{array}$} & Intervention & $21.33 \pm 6.48$ & $15.60 \pm 3.64$ & $13.80 \pm 3.69$ & \multirow{2}{*}{$5.98 * * *$} & \multirow{2}{*}{2,58} & \multirow{2}{*}{0.17} \\
\hline & Control & $21.38 \pm 5.57$ & $22.31 \pm 5.12$ & $20.94 \pm 4.63$ & & & \\
\hline \multirow{2}{*}{$\begin{array}{l}\text { Nonacceptance of emo- } \\
\text { tional responses }\end{array}$} & Intervention & $17.60 \pm 2.64$ & $12.87 \pm 3.34$ & $9.87 \pm 2.17$ & \multirow{2}{*}{$13.26^{* * *}$} & \multirow{2}{*}{2,58} & \multirow{2}{*}{0.31} \\
\hline & Control & $15.94 \pm 3.21$ & $15.81 \pm 3.95$ & $15.31 \pm 3.00$ & & & \\
\hline \multirow{3}{*}{ Lack of emotional clarity } & Intervention & $14.73 \pm 1.94$ & $12.73 \pm 2.74$ & $9.87 \pm 2.17$ & \multirow{3}{*}{$13.07 * * *$} & \multirow{3}{*}{2,58} & \multirow{3}{*}{0.31} \\
\hline & & & & & & & \\
\hline & Control & $14.69 \pm 2.15$ & $14.50 \pm 2.99$ & $14.63 \pm 1.82$ & & & \\
\hline \multirow{3}{*}{ Emotion Coaching (EC) } & Intervention & $18.47 \pm 2.42$ & $25.07 \pm 5.05$ & $23.93 \pm 3.99$ & \multirow{3}{*}{$7.08 * *$} & \multirow{3}{*}{2,58} & \multirow{3}{*}{0.20} \\
\hline & & & & & & & \\
\hline & Control & $19.75 \pm 1.98$ & $20.94 \pm 3.84$ & $20.88 \pm 3.22$ & & & \\
\hline \multirow{3}{*}{ Emotion Dismissing (ED) } & Intervention & $26.60 \pm 3.07$ & $20.87 \pm 3.11$ & $22.00 \pm 3.55$ & & & \\
\hline & & & & & $9.03 * * *$ & 2,58 & 0.24 \\
\hline & Control & $26.06 \pm 2.32$ & $26.25 \pm 2.89$ & $26.81 \pm 3.39$ & & & \\
\hline
\end{tabular}

$* \mathrm{P}<0.5 ; * * \mathrm{P}<0.01 ; * * * \mathrm{P}<0.001$. 
Table 3. Repeated measures ANOVA results for emotion regulation and emotion coaching

\begin{tabular}{|c|c|c|c|c|c|c|c|c|c|}
\hline \multirow{2}{*}{ Variable } & \multicolumn{3}{|c|}{$\begin{array}{l}\text { Pre-intervention } \\
\text { Post-intervention }\end{array}$} & \multicolumn{3}{|c|}{$\begin{array}{l}\text { Post-intervention - } \\
\text { Follow-up }\end{array}$} & \multicolumn{3}{|c|}{$\begin{array}{l}\text { Pre-intervention } \\
\text { Follow-up }\end{array}$} \\
\hline & $\mathbf{F}$ & df & $\eta^{2}$ & $\mathbf{F}$ & df & $\eta^{2}$ & $\mathbf{F}$ & df & $\eta^{2}$ \\
\hline Difficulties engaging in goal-directed behavior & 1.98 & 1,29 & 0.06 & $4.86^{*}$ & 1,29 & 0.14 & $21.19 * * *$ & 1,29 & 0.42 \\
\hline Impulse control difficulties & 1.90 & 1,29 & 0.06 & 0.47 & 1,29 & 0.02 & $5.28^{*}$ & 1,29 & 0.15 \\
\hline Lack of emotional awareness & 2.53 & 1,29 & 0.08 & $5.99 *$ & 1,29 & 0.17 & $20.41 * * *$ & 1,29 & 0.41 \\
\hline Limited access to emotion regulation strategies & $5.41^{*}$ & 1,29 & 0.16 & 0.67 & 1,29 & 0.02 & $6.80^{* *}$ & 1,29 & 0.19 \\
\hline Nonacceptance of emotional responses & $8.82^{* *}$ & 1,29 & 0.23 & 3.62 & 1,29 & 0.11 & $28.89 * * *$ & 1,29 & 0.50 \\
\hline Lack of emotional clarity & 3.47 & 1,29 & 0.11 & $7.57^{* *}$ & 1,29 & 0.21 & $40.27^{* * *}$ & 1,29 & 0.58 \\
\hline Emotion Coaching (EC) & $7.74^{* *}$ & 1,29 & 0.21 & 3.36 & 1,29 & 0.10 & $6.64^{*}$ & 1,29 & 0.19 \\
\hline Emotion Dismissing (ED) & $11.03 * * *$ & 1,29 & 0.28 & 0.90 & 1,29 & 0.03 & $8.07 * *$ & 1,29 & 0.22 \\
\hline
\end{tabular}

showed that the difference between the two groups on difficulties engaging in goal-directed behavior, lack of emotional awareness, limited access to emotion regulation strategies, nonacceptance of emotional responses, lack of emotional clarity, and maternal EC and ED was significant. In addition, no significant difference in impulse control difficulties was observed between the two groups. Mothers who attended the ECPP had significantly higher emotion regulation and EC while those in the control group indicated no change.

As Table 3 shows, the difference in the scores for limited access to emotion regulation strategies, nonacceptance of emotional responses, and maternal EC and ED from preintervention to post-intervention in two groups was significant. Also, there was a significant difference between post-intervention and follow-up in difficulties engaging in goal-directed behavior, lack of emotional awareness, and lack of emotional clarity between two groups. A significant difference in all emotion regulation and EC subscales was observed between pre-intervention and follow-up.

Table 4 shows means, standard deviations, and repeated measures ANOVA results for the child internalizing disorder and emotion regulation from pre-intervention to follow-up. Results of repeated measures ANOVA demonstrated that the between-group interaction effects for Time*Group were significant. Thus, it can be concluded with $95 \%$ confidence that the two groups were significantly different regarding the effectiveness of the ECPP in reducing the parent-reported emotional problem, anxiety/depression, and withdrawnness. The subscales of
ERC (lability/negativity, emotion regulation) did not significantly decrease from pre-intervention to follow-up.

As Table 5 shows, there was a significant difference in the scores for child emotion regulation between preand post-intervention in two group scores. However, no significant difference between the two groups was observed from post-intervention to follow-up. In general, both groups showed a significant difference in lability/ negativity and emotion regulation subscales of the ERC between pre-intervention and follow-up.

\section{Discussion}

The current study expands upon previous research by investigating the effects of ECPP on mothers of preschool children with a range of internalizing disorders in Iran. The primary purpose of the current study was to improve mothers' emotional awareness and emotion regulation skills.

The results of the current study indicated that mothers in the ECPP group showed a significant improvement in emotional awareness and emotion regulation from postintervention to follow-up. These results are consistent with the findings of Kehoe, Havighurst \& Harley (2014), Havighurst et al. (2010), and Havighurst, Wilson, Harley \& Prior (2009). These studies (Havighurst et al., 2013; Havighurst et al., 2009; Havighurst et al., 2010; Kehoe et al., 2014; Wilson, Havighurst \& Harley, 2012) have indicated that mothers who participated in ECPP reported lower levels of emotionally dismissive and disapproving beliefs. They also reported a lower level of ignoring child's negative emotions and a greater level of using 
Table 4. Mean $\pm S D$ and repeated measures ANOVA results for the child internalizing disorder and emotion regulation

\begin{tabular}{|c|c|c|c|c|c|c|c|}
\hline \multirow{3}{*}{ Variable } & \multirow{3}{*}{ Group } & \multicolumn{6}{|c|}{ Adjusted Mean } \\
\hline & & \multicolumn{3}{|c|}{ Mean $\pm S D$} & \multicolumn{3}{|c|}{ Group-by-Time Interaction } \\
\hline & & Pre-intervention & Post-intervention & Follow-up & Analysis (F) & df & $\eta^{2}$ \\
\hline \multirow{2}{*}{ Emotion proble } & Intervention & $7.20 \pm 1.78$ & $5.27 \pm 2.60$ & $2.80 \pm 2.40$ & $3.63^{*}$ & 2,58 & 0.11 \\
\hline & Control & $7.13 \pm 2.28$ & $6.44 \pm 3.31$ & $6.25 \pm 3.02$ & & & \\
\hline \multirow{2}{*}{ Anxiety / depres } & Intervention & $7.73 \pm 2.55$ & $5.33 \pm 2.94$ & $3.40 \pm 1.99$ & $3.94 *$ & 2,58 & 0.12 \\
\hline & Control & $7.81 \pm 2.34$ & $6.88 \pm 2.96$ & $7.38 \pm 3.26$ & & & \\
\hline \multirow{2}{*}{ Somatizatior } & Intervention & $6.33 \pm 3.98$ & $4.80 \pm 2.91$ & $2.93 \pm 1.62$ & 3.07 & 2,58 & 0.10 \\
\hline & Control & $5.69 \pm 2.63$ & $5.81 \pm 2.51$ & $5.63 \pm 2.75$ & & & \\
\hline \multirow{2}{*}{ Withdrawnne } & Intervention & $5.53 \pm 2.75$ & $3.53 \pm 1.85$ & $1.80 \pm 1.42$ & $4.98 * *$ & 2,58 & 0.15 \\
\hline & Control & $5.31 \pm 3.20$ & $5.19 \pm 3.17$ & $6.19 \pm 3.76$ & & & \\
\hline \multirow{2}{*}{ Lability / negat } & Intervention & $39.13 \pm 10.04$ & $29.13 \pm 11.10$ & $23.00 \pm 5.25$ & 2.88 & 2,58 & 0.09 \\
\hline & Control & $37.13 \pm 11.37$ & $34.75 \pm 8.87$ & $32.63 \pm 7.33$ & & & \\
\hline \multirow{2}{*}{ Emotion regula } & Intervention & $14.80 \pm 3.76$ & $18.40 \pm 3.54$ & $19.40 \pm 4.00$ & 2.94 & 2,58 & 0.09 \\
\hline & Control & $15.25 \pm 3.66$ & $14.56 \pm 5.23$ & $14.94 \pm 4.27$ & & & \\
\hline
\end{tabular}

emotional coaching in response to their child's emotions. The improvements obtained were in line with the parenting style trained in the ECPP protocol.

Better emotional awareness and emotion regulation skills are associated with increased intimacy and closeness in relationships (Schutte et al., 2001). Part of the parent-child adaptive interaction depends on the parent's ability to identify and be aware of their and their child's emotions (Gottman \& DeClaire, 1997; Halberstadt, Denham \& Dunsmore, 2001). In ECPP, parents become familiar with the physiological, cognitive, and behavioral aspects of emotional experiences and learn how to identify emotions behind verbal statements, behaviors, or body language. In addition, parents are asked to visualize the adult-like situation for their child and to think about how he or she feels. Representing the child's emotional experiences in this way and seeing this as an opportunity to understand the child's emotions and teaching them about managing their emotions can calm parents (Gross \& John, 2003).

Reducing parents' emotional response and heightening their tolerance and understanding of their child's emotional experiences can lead to a decrease in the intensity and extent of parent-child conflict (Eisenberg, Cumberland \&
Spinrad, 1998). Our results from the mothers participating in the intervention group showed that mothers tend to use emotion naming and discussing the causes and consequences of children's emotions. They showed a greater capacity to talk to their children about emotion management, which is a key feature of ECPP. We found that emotion dialogue is significantly associated with EC (Lunkenheimer et al., 2007), leading to emotion management (Salmon, Dadds, Allen \& Hawes, 2009) and greater emotional competence in children (Dunn, Brown, \& Beardsall, 1991). Mothers also reported greater empathy, which is a key feature of communicating and responding effectively to children's emotions (De Paul \& Guibert, 2008).

The second hypothesis of the current study was to improve child internalizing disorders and child emotion regulation skills. The results showed that children in both ECPP and control groups made improvements in emotional instability/negativity but the improvement in the intervention group was significantly greater. The ECPP group also showed a significant improvement in emotion regulation, while there was no significant improvement in emotion regulation for the control group. Part of this improvement in both groups may be due to normal developmental changes in preschool children (Tobin, Sansosti 
Table 5. Repeated measures ANOVA results for the child internalizing disorder and emotion regulation

\begin{tabular}{|c|c|c|c|c|c|c|c|c|c|}
\hline \multirow{2}{*}{ Variable } & \multicolumn{3}{|c|}{ Pre-intervention, Post-intervention } & \multicolumn{3}{|c|}{ Post-Follow-up } & \multicolumn{3}{|c|}{ Pre-Follow-up } \\
\hline & $\mathbf{F}$ & df & $\eta^{2}$ & $\mathbf{F}$ & df & $\eta^{2}$ & $\mathbf{F}$ & df & $n^{2}$ \\
\hline Emotion problem & 1.00 & 1,29 & 0.03 & 2.45 & 1,29 & 0.08 & $7.72^{* *}$ & 1,29 & 0.21 \\
\hline Anxiety / depression & 1.13 & 1,29 & 0.04 & 2.70 & 1,29 & 0.09 & $8.41 * *$ & 1,29 & 0.22 \\
\hline Somatization & 1.30 & 1,29 & 0.04 & 2.00 & 1,29 & 0.06 & $5.81^{*}$ & 1,29 & 0.17 \\
\hline Withdrawnness & 2.36 & 1,29 & 0.08 & 3.18 & 1,29 & 0.10 & $8.07 * *$ & 1,29 & 0.22 \\
\hline Lability / negativity & 1.94 & 1,29 & 0.06 & 0.68 & 1,29 & 0.02 & $7.03^{* *}$ & 1,29 & 0.20 \\
\hline Emotion regulation & $5.11^{*}$ & 1,29 & 0.15 & 0.06 & 1,29 & 0.001 & $5.10^{*}$ & 1,29 & 0.15 \\
\hline
\end{tabular}

\& McIntyre, 2007). However, children whose mothers participated in ECPP showed more improvement than the control group. This is consistent with Merchant's (2018) findings who indicated that there is a significant positive relationship between mother's EC and the child's ability to regulate their emotions. In addition, Ellis et al. (2014) study showed that children of parents who participated in ECPP were more likely to be emotionally regulated. Another study has indicated that EC influences children's emotion regulation (Ramsden \& Hubbard, 2002).

Previous studies have also suggested that the negative reactions of parents to children's emotions are associated with poor emotion regulation in children (Gottman et al., 1996). Research on the early childhood stage has also shown a significant relationship between the level of discussion about parent-child emotions and emotion regulation (Dunn et al., 1991); However, damage to child emotion regulation is expected at different developmental stages (Denham et al., 2000; Eisenberg, Fabes \& Murphy, 1996). According to ERC scores, the ECPP group significantly used more emotional labels and emotion exploration for their children than the control group at follow-up. Describing and discussing emotions is one of the key components of ECPP (Lunkenheimer et al., 2007). Lunkenheimer et al. (2007) have shown that EC and emotional neglect have a strong association with a low level of emotional instability/ negativity and internalizing behavioral problems. Similar findings indicate that EC has an indirect and protective effect on children's emotion regulation (Katz \& Gottman, 1997). ECPP includes naming emotions and emotion validation. In addition, one of the goals of the intervention is to reduce dismissing parenting style by moderating their beliefs about children's emotions.
Many mothers of the current study initially ignored the emotions. However, mothers in the intervention group were encouraged to consider the emotional experiences of family members, especially the child, and to empathize with child emotions during parent-child interaction. Obtaining information about the emotional experiences of family members may help break down intergenerational patterns of negative parenting (Leerkes \& Crockenberg, 2006). Mothers of the ECPP group reported new ideas about taking children's emotions as an opportunity to be close to them and educate them (rather than avoiding, suppressing, or controlling emotions) over time. Mothers with emotion dysregulation may lack the emotional comprehension skills required to respond appropriately to the child's negative emotions (Dunsmore, Booker \& Ollendick, 2013).

Our results showed that there was a significant decrease in the symptoms of internalizing disorders from preintervention to follow up in the ECPP group compared with the control group. The results are in line with the findings of Kehoe et al. (2014) who found that turning into kids program significantly improves parental emotion socialization and reduces children's internalizing difficulties in the intervention group. Havighurst et al. (2013) also showed that ECPP significantly reduced the extent and severity of behavioral problems, indicating that this treatment is effective for childhood disorders. A randomized controlled study by Edrissi et al. (2019) demonstrated a significant difference between participants in the parenting program group and control group on parent-reported anxiety at post-test and 6-month follow-up. Our results are important because few parenting programs have shown improvement in symptoms of children's internalizing disorders. 
By using emotional response along with acceptance and validation, parents not only facilitate more intimate and emotional relationships but also provide a supportive environment for the child to feel comfortable expressing their feelings. This may reduce the intensity and timing of emotional experiences and allow the child to analyze their emotions by focusing on (Gottman, Katz \& Hooven, 2013; Shenk \& Fruzzetti, 2011), instead of internalizing them. On the other hand, these conversations lead to learning new strategies (such as representing or accepting emotions) to regulate negative emotions (Bastian et al., 2012; Gross \& John, 2003), rather than trying to prevent thinking about them (such as suppression), which leads to intense emotional experiences (Bastian et al., 2012).

\section{Limitation and suggestion}

The main limitation of the current study was the evaluation of the internalizing disorders of children using the parent CBCL, which may be affected by expectancy bias. Future studies should use multimodal assessments, such as interviewing children along with parental reports. Another limitation of the current study was that the followup period was limited to 3 months. More studies with longer follow-up periods are necessary to examine the effects of the intervention. In addition, a high number of items used in the questionnaires could influence the results. It is necessary for future studies to use measures that have fewer questions to reduce the burden on participants. Moreover, the role of fathers was not considered due to time constraints and limited facilities. Examining the effects of ECPP on both parents in the Iranian population is needed. Our findings were limited to children with internalizing disorders. It will be helpful to assess the effects of ECPP on other disorders in the future. It is also beneficial for future studies to use a larger sample size to improve the generalizability of the results. A comparison of the ECPP with other interventions is also recommended.

\section{Conclusion}

The results of the current study showed that ECPP is effective in enhancing mothers' emotion regulation and emotional awareness with children with internalizing disorders. In addition, ECPP improved children's emotion regulation and internalizing disorders. This study shows the initial indicated the usability of ECPP as an effective treatment for Iranian preschool children with internalizing disorders.

\section{Ethical Considerations}

\section{Compliance with ethical guidelines}

The study was approved by the ethical committee of Shahid Beheshti University of Medical Sciences with IR.SBMU. MSP.REC.1397.340 ethical code. All mothers were informed of the aims and processes of the study and provided informed consent for and their children.

\section{Funding}

This research did not receive any grant from funding agencies in the public, commercial, or non-profit sectors.

\section{Authors' contributions}

Investigation and writing - original draft: Pegah Pezeshki; Data collection and data analysis: Hoda Doos Ali Van anMaryam Aslzaker; Supervision Mehdi Jafari.

\section{Conflict of interest}

There is no conflict of interest in current article.

\section{References}

Achenbach, T. M., Dumenci, L., \& Rescorla, L. A. (2003) DSM-oriented and empirically based approaches to constructing scales from the same item pools. Journal of Clinical Child E Adolescent Psychology, 32(3), 328-40. [DOI:10.1207/ S15374424JCCP3203_02] [PMID]

Achenbach, T. M., Howell, C. T., Quay, H. C., \& Conners, C. K. (1991). National survey of problems and competencies among four-to sixteen-year-olds: Parents' reports for normative and clinical samples. Monographs of the Society for Research in Child Development, 56(3), 1-131. [DOI:10.2307/1166156] [PMID]

Achenbach, T. M., \& Rescorla, L. Manual for the ASEBA adult forms $\mathcal{E}$ profiles: For ages 18-59: Adult self-report and adult behavior checklist. The Achenbach System of Empirically Based Assessment; 2003. https://books.google.com/ books?id=Gv6rAAAACAAJ\&dq

Achenbach, T., \& Rescorla, L. (2000). Manual for the ASEBA preschool ffrms \& profiles: An Integrated system of multi-informant assessment. Burlington: University of Vermont Department of Psychiatry. Coleman, PK, \& Karraker, KH (2003). Maternal self-efficacy beliefs, competence in parenting, and toddlers' behavior and developmental status. Infant Mental Health Journal, 24(2), 126-48

American Psychiatric Association. (2013). Diagnostic and statistical manual of mental disorders (DSM-5®). Washington, DC: American Psychiatric Pub. https://books.google.com/books?id=JivBAAAQBAJ\&dq 
Bastian, B., Kuppens, P., Hornsey, M. J., Park, J., Koval, P., \& Uchida, Y. (2012). Feeling bad about being sad: The role of social expectancies in amplifying negative mood. Emotion, 12(1), 69-80. [DOI:10.1037/a0024755] [PMID]

Carlson, S. M., \& Wang, T. S. (2007). Inhibitory control and emotion regulation in preschool children. Cognitive Development, 22(4), 489510. [DOI:10.1016/j.cogdev.2007.08.002]

Crespo, L. M., Trentacosta, C. J., Aikins, D., \& Wargo-Aikins, J. (2017) Maternal emotion regulation and children's behavior problems: The mediating role of child emotion regulation. Journal of Child and Family studies, 26(10), 2797-809. [DOI:10.1007/s10826-017-0791-8]

Danisman, S., Dereli, I. E., Akin, D. Z., \& Yaya, D. (2016). Examining the psychometric properties of the Emotional Regulation Checklist in 4-and 5-year-old preschoolers. Electronic Journal of Research in Educational Psychology, 14(3), 534-56. [DOI:10.14204/ ejrep.40.15124]

Davis, S., Votruba-Drzal, E., \& Silk, J. S. (2015). Trajectories of internalizing symptoms from early childhood to adolescence: Associations with temperament and parenting. Social Development, 24(3), 501-20. [DOI:10.1111/sode.12105]

De Paul, J., \& Guibert, M. (2008). Empathy and child neglect: A theoretical model. Child Abuse \& Neglect, 32(11), 1063-71. [DOI:10.1016/j.chiabu.2008.03.003] [PMID]

de Veld, D. M. J., Riksen-Walraven, J. M., \& de Weerth, C. (2012). The relation between emotion regulation strategies and physiological stress responses in middle childhood. Psychoneuroendocrinology, 37(8), 1309-19. [DOI:10.1016/j.psyneuen.2012.01.004] [PMID]

Denham, S. A., Workman, E., Cole, P. M., Weissbrod, C., Kendziora K. T., \& Zahn-Waxler, C. (2000). Prediction of externalizing behavior problems from early to middle childhood: The role of parental socialization and emotion expression. Development and Psychopathology, 12(1), 23-45. [DOI:10.1017/S0954579400001024] [PMID]

Dunn, J., Brown, J., \& Beardsall, L. (1991). Family talk about feeling states and children's later understanding of others' emotions. Developmental Psychology, 27(3), 448-55. [DOI:10.1037/00121649.27.3.448]

Dunsmore, J. C., Booker, J. A., \& Ollendick, T. H. (2013). Parental emotion coaching and child emotion regulation as protective factors for children with oppositional defiant disorder. Social Development, 22(3), 444-66. [DOI:10.1111/j.1467-9507.2011.00652.x] [PMID] [PMCID]

Edrissi, F., Havighurst, S. S., Aghebati, A., Habibi, M., \& Arani, A. M. (2019). A pilot study of the tuning in to kids parenting program in Iran for reducing preschool children's anxiety. Journal of Child and Family Studies, 28(6), 1695-702. [DOI:10.1007/s10826-019-01400-0]

Eisenberg, N. (2001). The core and correlates of affective social competence. Social Development, 10(1), 120-4. [DOI:10.1111/1467-9507.00151]

Eisenberg, N., Cumberland, A., \& Spinrad, T. L. (1998). Parental socialization of emotion. Psychological Inquiry, 9(4), 241-73. [DOI:10.1207/s15327965pli0904_1] [PMID] [PMCID]

Eisenberg, N., Cumberland, A., Spinrad, T. L., Fabes, R. A., Shepard, S. A., \& Reiser, M., et al. (2001). The relations of regulation and emotionality to children's externalizing and internalizing problem behavior. Child Development, 72(4), 1112-34. [DOI:10.1111/1467-8624.00337] [PMID]
Eisenberg, N., Fabes, R. A., \& Murphy, B. C. (1996). Parents' reactions to children's negative emotions: Relations to children's social competence and comforting behavior. Child Development, 67(5), 2227-47. [DOI:10.2307/1131620] [PMID]

Ellis, B. H., Alisic, E., Reiss, A., Dishion, T., \& Fisher, P. A. (2014). Emotion regulation among preschoolers on a continuum of risk: The role of maternal emotion coaching. Journal of Child and Family Studies, 23(6), 965-74. [DOI:10.1007/s10826-0139752-z] [PMID] [PMCID]

Erskine, H. E., Baxter, A. J., Patton, G., Moffitt, T. E., Patel, V., \& Whiteford, H. A., et al. (2017). The global coverage of prevalence data for mental disorders in children and adolescents. Epidemiology and Psychiatric Sciences, 26(4), 395-402. [DOI:10.1017/S2045796015001158] [PMID] [PMCID]

Esbensen, A. J., Hoffman, E. K., Shaffer, R., Chen, E., Patel, L., \& Jacola, L. (2018). Reliability of parent report measures of behaviour in children with Down syndrome. Journal of Intellectual Disability Research, 62(9), 785-97. [DOI:10.1111/jir.12533] [PMID] [PMCID]

Ghanbari, S., Esmaili, Z., Porebrahim, T., \& Kholghi, H. (2017). [The role of marital boredom with the mediation of the quality of maternal care in anticipation of externalizing and internalizing problems of children (Persian)]. Journal of Psychological Models and Methods, 7(26):55-72. http://jpmm.miau.ac.ir/article_2286.html

Gilliom, M., \& Shaw, D. S. (2004). Codevelopment of externalizing and internalizing problems in early childhood. Development and Psychopathology, 16(2), 313-33. [DOI:10.1017/ S0954579404044530] [PMID]

Gottman, J. M., \& DeClaire, J. (1997). The heart of parenting: How to raiseanemotionally intelligent child. New York:Simon\&Schuster https:/ / books.google.com/books?id=64pdPgAACAAJ\&dq

Gottman, J. M., Katz, L. F., \& Hooven, C. (1996). Parental metaemotion philosophy and the emotional life of families: Theoretical models and preliminary data. Journal of Family Psychology, 10(3), 243-68. [DOI:10.1037/0893-3200.10.3.243]

Gottman, J. M., Katz, L. F., \& Hooven, C. (2013). Meta-emotion: How families communicate emotionally. New York: Routledge. [DOI:10.4324/9780203763568]

Gratz, K. L., \& Roemer, L. (2004). Multidimensional assessment of emotion regulation and dysregulation: Development, factor structure, and initial validation of the difficulties in emotion regulation scale. Journal of Psychopathology and Behavioral Assessment, 26(1), 41-54. [DOI:10.1023/ B:JOBA.0000007455.08539.94]

Graziano, P. A., Reavis, R. D., Keane, S. P., \& Calkins, S. D. (2007). The role of emotion regulation in children's early academic success. Journal of School Psychology, 45(1), 3-19. [DOI:10.1016/j.jsp.2006.09.002] [PMID] [PMCID]

Gross, J. J., \& John, O. P. (2003). Individual differences in two emotion regulation processes: Implications for affect, relationships, and well-being. Journal of Personality and Social Psychology, 85(2), 348-62. [DOI:10.1037/0022-3514.85.2.348] [PMID]

Gus, L., Rose, J., \& Gilbert, L. (2015). Emotion coaching: A universal strategy for supporting and promoting sustainable emotional and behavioural well-being. Educational and Child Psychology, 32(1), 31-41. https://discovery.dundee.ac.uk/en/ publications/emotion-coaching-a-universal-strategy-for-supporting-and-promotin 
Halberstadt, A. G., Denham, S. A., \& Dunsmore, J. C. (2001). Affective social competence. Social Development, 10(1), 79-119. [DOI:10.1111/1467-9507.00150]

Harden, B. J., Panlilio, C., Morrison, C., Duncan, A. D., Duchene, M., \& Clyman, R. B. (2017). Emotion regulation of preschool children in foster care: The influence of maternal depression and parenting. Journal of Child and Family Studies, 26(4), 112434. [DOI:10.1007/s10826-016-0636-x]

Havighurst, S. S., Wilson, K. R., Harley, A. E., Kehoe, C., Efron, D., \& Prior, M. R. (2013). “Tuning into kids": Reducing young children's behavior problems using an emotion coaching parenting program. Child Psychiatry \& Human Development, 44(2), 247-64. [DOI:10.1007/s10578-012-0322-1] [PMID]

Havighurst, S. S., Wilson, K. R., Harley, A. E., \& Prior, M. R. (2009). Tuning in to kids: An emotion-focused parenting program-initial findings from a community trial. Journal of Community Psychology, 37(8), 1008-23. [DOI:10.1002/jcop.20345]

Havighurst, S. S., Wilson, K. R., Harley, A. E., Prior, M. R., \& Kehoe, C. (2010). Tuning in to Kids: Improving emotion socialization practices in parents of preschool children--findings from a community trial. The Journal of Child Psychology and Psychiatry, 51(12), 1342-50. [DOI:10.1111/j.1469-7610.2010.02303.x] [PMID]

In-Albon, T. (2012). [State of research on internalizing disorders in children and adolescents: Is it still in its infancy? (Aktueller stand internalisierender störungen im kindes- und jugendalter: Sind sie aus den kinderschuhen ausgewachsen?) (German)]. Verhaltenstherapie, 22, 246-57. [DOI:10.1159/000345231]

Ivcevic, Z., \& Brackett, M. (2014). Predicting school success: Comparing conscientiousness, grit, and emotion regulation ability. Journal of Research in Personality, 52, 29-36. [DOI:10.1016/j. jrp.2014.06.005]

Katz, L. F., \& Gottman, J. M. (1997). Buffering children from marital conflict and dissolution. Journal of Clinical Child Psychology, 26(2), 157-71. [DOI:10.1207/s15374424jccp2602_4] [PMID]

Kehoe, C. E., Havighurst, S. S., \& Harley, A. E. (2014). Tuning in to teens: Improving parent emotion socialization to reduce youth internalizing difficulties. Social Development, 23(2), 41331. [DOI:10.1111/sode.12060]

Khanzadeh, M., Saeediyan, M., Hosseinchari, M., \& Edrissi, F. (2012). [Factor structure and psychometric properties of difficulties in emotional regulation scale (Persian)]. International Journal of Behavioral Sciences, 6(1), 87-96. http://www.behavsci.ir/article_67768.html

Kidwell, S. L., Young, M. E., Hinkle, L. D., Ratliff, A. D., Marcum, M. E., \& Martin, C. N. (2010). Emotional competence and behavior problems: Differences across preschool assessment of attachment classifications. Clinical Child Psychology and Psychiatry, 15(3), 391-406. [DOI:10.1177/1359104510367589] [PMID]

Kim, J., \& Cicchetti, D. (2010). Longitudinal pathways linking child maltreatment, emotion regulation, peer relations, and psychopathology. Journal of Child Psychology and Psychiatry, 51(6), 706-16. [DOI:10.1111/j.1469-7610.2009.02202.x] [PMID] [PMCID]

Lagacé-Séguin, D. G., \& Coplan, R. J. (2005). Maternal emotional styles and child social adjustment: Assessment, correlates, outcomes and goodness of fit in early childhood. Social Development, 14(4), 613-36. [DOI:10.1111/j.1467-9507.2005.00320.x]
Leerkes, E. M., \& Crockenberg, S. C. (2006). Antecedents of mothers' emotional and cognitive responses to infant distress: The role of family, mother, and infant characteristics. Infant Mental Health Journal, 27(4), 405-28. [DOI:10.1002/imhj.20099] [PMID]

Loop, L., \& Roskam, I. (2016). Do children behave better when parents' emotion coaching practices are stimulated? A microtrial study. Journal of Child and Family Studies, 25(7), 2223-35. [DOI:10.1007/s10826-016-0382-0]

Lunkenheimer, E. S., Shields, A. M., \& Cortina, K. S. (2007). Parental emotion coaching and dismissing in family interaction. Social Development, 16(2), 232-48. [DOI:10.1111/j.14679507.2007.00382.x]

Merchant, E. K. (2018). An exploration of the impact of attachment, parental meta-emotion, and emotion regulation in adoptive families [PhD. dissertation]. Greensboro: The University of North Carolina at Greensboro. https:// search.proquest.com/openview/268ffc639becdfbfa3971b3bab61516b/1

Pourhossein, R., Habibi, M., Ashoori, A., Ghanbari, N., Riahi, Y., \& Ghodrati, S. (2015). Prevalence of behavioral disorders among preschool children. Journal of Fundamentals of Mental Health, 17(5), 234-239. https://jfmh.mums.ac.ir/jufile?ar_ sfile $=280252$

Morris, A. S., Silk, J. S., Steinberg, L., Myers, S. S., \& Robinson, L. R. (2007). The role of the family context in the development of emotion regulation. Social Development, 16(2), 361-88. [DOI:10.1111/j.1467-9507.2007.00389.x] [PMID] [PMCID]

Pourhossein, R., Habibi, M., Ashoori, A., Ghanbari, N., Riahi, Y., \& Ghodrati, S. (2015). [Prevalence of behavioral disorders among preschool children (Persian)]. Journal of Fundamentals of Mental Health, 17(5), 234-9. [DOI:10.22038/JFMH.2015.4794]

Ramsden, S. R., \& Hubbard, J. A. (2002). Family expressiveness and parental emotion coaching: Their role in children's emotion regulation and aggression. Journal of Abnormal Child Psychology, 30(6), 657-67. [DOI:10.1023/A:1020819915881] [PMID]

Salmon, K., Dadds, M. R., Allen, J., \& Hawes, D. J. (2009). Can emotional language skills be taught during parent training for conduct problem children? Child Psychiatry and Human Development, 40(4), 485-98. [DOI:10.1007/s10578-009-0139-8] [PMID]

Sanders, D. E., Merrell, K. W., \& Cobb, H. C. (1999). Internalizing symptoms and affect of children with emotional and behavioral disorders: A comparative study with an urban African American sample. Psychology in the Schools, 36(3), 187-97. [DOI:10.1002/(SICI)1520-6807(199905)36:3<187::AIDPITS2>3.0.CO;2-S]

Schutte, N. S., Malouff, J. M., Bobik, C., Coston, T. D., Greeson, C., \& Jedlicka, C., et al. (2001). Emotional intelligence and interpersonal relations. The Journal of Social Psychology, 141(4), 523-36. [DOI:10.1080/00224540109600569] [PMID]

Shenk, C. E., \& Fruzzetti, A. E. (2011). The impact of validating and invalidating responses on emotional reactivity. Journal of Social and Clinical Psychology, 30(2), 163-83. [DOI:10.1521/ jscp.2011.30.2.163]

Shields, A., \& Cicchetti, D. (1997). Emotion regulation among school-age children: The development and validation of a new criterion Q-sort scale. Developmental Psychology, 33(6), 906-16. [DOI:10.1037/0012-1649.33.6.906] [PMID] 
Shipman, K. L., \& Zeman, J. (2001). Socialization of children's emotion regulation in mother-child dyads: A developmental psychopathology perspective. Development and Psychopathology, 13(2), 317-36. [DOI:10.1017/S0954579401002073] [PMID]

Shiri, I., Valipour, M., Mazaheri, M. A., \& Roudbari Saghaee, B. (2014). [Prevalence of internalized and externalized behavioral problem among middle school boys in Zanjan city (Persian)]. Journal of Research in Behavioural Sciences, 12(2), 165-73. http:/ / rbs.mui.ac.ir/article-1-369-en.html

Soleimani, H., \& Bashash, L. (2012). [Factor structure, validity and reliability of the Maternal Emotional Styles Questionnaire (MESQ) (Persian)]. Knowledge \& Research in Applied Psychology, 13(1), 38-47. http://pdfarchive.ir/pack-14/Do_33413914705. pdf

Tandon, M., Cardeli, E., \& Luby, J. (2009). Internalizing disorders in early childhood: A review of depressive and anxiety disorders. Child and Adolescent Psychiatric Clinics, 18(3), 593-610. [DOI:10.1016/j.chc.2009.03.004] [PMID] [PMCID]

Thompson, R. A. (1994). Emotion regulation: A theme in search of definition. Monographs of the Society for Research in Child Development, 59(2-3), 25-52. [DOI:10.1111/j.1540-5834.1994. tb01276.x]

Tobin, R. M., Sansosti, F. J., \& McIntyre, L. L. (2007). Developing emotional competence in preschoolers: A review of regulation research and recommendations for practice. The California School Psychologist, 12(1), 107-20. [DOI:10.1007/BF03340935]

Trentacosta, C. J., \& Shaw, D. S. (2009). Emotional self-regulation, peer rejection, and antisocial behavior: Developmental associations from early childhood to early adolescence. Journal of Applied Developmental Psychology, 30(3), 356-65. [DOI:10.1016/j. appdev.2008.12.016] [PMID] [PMCID]

Wilson, K. R., Havighurst, S. S., \& Harley, A. E. (2012). Tuning in to Kids: An effectiveness trial of a parenting program targeting emotion socialization of preschoolers. Journal of Family Psychology, 26(1), 56-65. [DOI:10.1037/a0026480] [PMID]

Zeman, J., Shipman, K., \& Suveg, C. (2002). Anger and sadness regulation: Predictions to internalizing and externalizing symptoms in children. Journal of Clinical Child \& Adolescent Psychology, 31(3), 393-8. [DOI:10.1207/S15374424JCCP3103_11] [PMID] 
This Page Intentionally Left Blank 